\title{
Entre a Psicanálise e a Teoria Política: um diálogo com Jane Flax
}

\author{
Miriam Adelman \\ Universidade Federal do Paraná \\ Miriam Pillar Grossi \\ Universidade Federal de Santa Catarina
}

\begin{abstract}
Em outubro de 2001, tivemos o prazer de receber a teórica feminista Jane Flax, como conferencista no Il Encontro de Estudos de Gênero: Corpo, Sujeito, Poder, organizado pelo Núcleo de Estudos de Gênero da Universidade Federal do Paraná (UFPR), e também como convidada da Universidade Federal de Santa Catarina (UFSC) e da Revista Estudos Feministas para proferir a palestra intitulada Pensamento Feminista e a Teoria Política na Pós-Modernidade. Professora de Teoria Política na Howard University e psicanalista, Jane Flax é conhecida no mundo inteiro por sua contribuição à teoria social contemporânea e, em particular, pela construção de diálogos mais ricos e frutíferos entre três vertentes do pensamento social atual: a Psicanálise, a Filosofia Pós-Moderna e a Teoria Feminista. Atualmente, ela trabalha com o entrecruzamento de questões de gênero e raça na cultura e na política dos Estados Unidos. Assim, sua obra aborda diversos níveis de análise social: desde a subjetividade e a organização dos afetos até a relação destes com o pensamento acadêmico; das formas de poder que permeiam nosso cotidiano à reconstrução do nosso pensamento sobre as instituições políticas à luz das questões de gênero e raça. Suas reflexões se engajam nos debates da atualidade sobre a contribuição e os limites do pensamento pós-moderno para a teoria social contemporânea e também sobre a relação entre esse pensamento e a teoria feminista. Nesse sentido, sua obra, tal como transparece nesta entrevista, nos oferece uma série de desafios, fornecendo instrumentos para refletir sobre a reconstrução tanto das teorias sociais quanto das relações entre indivíduos no mundo contemporâneo.
\end{abstract}

Copyright (C) 2002 by Revista Estudos Feministas 
Miriam Adelman: Jane, como membro de uma geração que contribuiu para e foi em grande medida responsável pela introdução de formas radicalmente novas de pensar sobre sociedade, cultura e política, gostaria que você iniciasse esta entrevista com alguns comentários sobre sua formação intelectual e política, sobre sua formação acadêmica desde a graduação, os autores, professores, pessoas e teorias que mais a influenciaram.

Jane Flax: Minha formação inicial foi em Teoria Política. Claro que quando eu estava na graduação ainda não existia teoria feminista, mas eu já estava interessada em política. Quando eu estava no segundo grau me envolvi no Movimento de Direitos Civis e no Movimento contra a Guerra do Vietnã. Meu interesse em Teoria Política era também uma busca de um jeito de falar sobre política de uma forma mais filosófica, mais reflexiva. Como aluna de graduação em Berkeley tive a sorte de conversar e de estudar com um número de cientistas políticos maravilhosos como Sheldon Wolin, Hannah Pitkin e Norman Jackobson. Berkeley era um importante centro de Teoria Política e eu estudei toda a história da Teoria Política ocidental, iniciando com os pré-socráticos e indo até o século $X X$. Eu estava particularmente interessada no pensamento social germânico e tive cursos maravilhosos com um professor chamado Carl Schorske, que tinha escrito muito sobre Freud e a Filosofia Germânica. Isso foi realmente minha formação e continua sendo uma parte de minha área de reflexão. Eu estava também interessada nas relações entre conhecimento e poder e pensando sobre diferentes Teorias da Justiça, evidentemente porque esse era todo meu interesse político na época da graduação. Tínhamos apenas uma mulher como professora, Hannah Pitkin, que era realmente incrível e falava muito de Wittgenstein. Eu fiz minha monografia (Senior Honors Thesis) e ela foi muito importante para meu desenvolvimento intelectual. Ela estava escrevendo seu livro sobre Wittgenstein e Justiça. Nós estudávamos também bastante Teoria Lingüística. Então, quando fui fazer a pós-graduação em Yale, foi justamente quando emergiu a 'segunda onda' do feminismo norteamericano. Em 1969, eu fui para a pós-graduação em Yale e esse novo feminismo (New Haven Women's Movement) cresceu imensamente nos anos em que eu estava lá, até 1974. Eu estava muito envolvida com o Movimento de Mulheres, no Women's Center, organizando vários grupos de discussão com mulheres, ajudando mulheres espancadas que procuravam o centro, outras que tinham problemas e que vinham para conversar e receber ajuda. Por isso, durante todo o tempo em que permaneci na pós-graduação estive envolvida tanto com a teoria feminista quanto com o movimento feminista.

Em Yale, estudei também Teoria Política e Filosofia e escrevi 
minha dissertação sobre a relação entre conhecimento e poder, época em que comecei a estudar Foucault e também os teóricos críticos: Horkheimmer, Adorno, Marcuse. Foi quando também comecei a me interessar por Psicanálise, porque a teoria crítica depende muito fortemente de Freud e da Psicanálise dos primeiros tempos. Nesse momento pensei: "Bom, eu só posso realmente entender Psicanálise se eu praticá-la". É por isso que comecei a trabalhar como psicanalista, e como parte de minha formação eu passei a atender pacientes. Mas com o tempo, o atendimento a pacientes cresceu.

Era também o período no qual as pessoas estavam começando a escrever sobre feminismo e eu estava envolvida na primeira revista americana feminista, chamada Quest, que era dirigida para mulheres interessadas em teoria, mas também engajadas ativamente no movimento feminista. Trabalhava nisso quando me mudei para Washington em 1978 e escrevi os primeiros artigos sobre teoria feminista. Meu envolvimento em ajudar a desenvolver a teoria feminista estava relacionado com o início da segunda onda do feminismo. Eu estava definitivamente influenciada tanto por meu envolvimento no movimento de mulheres quanto por meu envolvimento anterior com o Movimento dos Direitos Civis e contra a guerra (do Vietnã).

MA: Você, como outras teóricas feministas da sua geração, encontrou-se no diálogo com outras teorias. Imagino que deve ter surgido um momento em que o elemento de gênero que faltava tomou forma. Como foi que isso aconteceu na sua experiência? Quando foi que você realmente percebeu a necessidade de desenvolver uma abordagem feminista para algumas dessas questões?

JF: Claro, na Psicanálise há muitas discussões sobre gênero, mas não necessariamente em uma linha muito feminista, e é por isso que algumas críticas feministas iniciais giravam em torno da forma como Freud e outros psicanalistas construíram a mulher. Algumas mulheres queriam rejeitar Freud, mas esse nunca foi meu sentimento, porque eu acreditava na importância do inconsciente e do desejo, e também porque minha visão era um pouco diferente. Por ser tanto psicanalista clínica como teórica feminista, pude ver o poder da perspectiva psicanalítica. Por isso, observei que, em uma perspectiva feminista, era possível desconstruir algumas idéias que, no fundo, eram uma forma de defesa masculina ou muito usadas para manter algum tipo de dominação masculina, o que me forneceu uma perspectiva diferente.

Também porque eu estava interessada em Filosofia Política, comecei a pensar sobre formas nas quais teorias políticas são construídas para proteger um certo tipo de relações de poder. Meus primeiros trabalhos eram uma revisão de autores como 
' FLAX, 1991.

Rousseau e Hobbes, e eu buscava em suas obras ver as formas como (o) gênero afeta as formas de escrever tanto sobre política quanto sobre família. Não estava interessada em tentar especular sobre a infância de Rousseau ou em saber como era seu mundo interno particular. Mas achava que era possível usar a perspectiva feminista psicanalítica para pensar sobre a forma em que o gênero participa do modo como as pessoas constroem o mundo, não necessariamente relacionando-o apenas com as mulheres, porque constroem certas visões sobre a política, ou porque colocam alguma coisa no privado em oposição ao público. Alguns quebra-cabeças na Teoria Política parecem mais evidentes quando se começa a pensar com um tipo de orientação de gênero. Da mesma forma, quando se começa a ficar preocupada sobre as formas como as relações de gênero afetam a organização da sociedade e nossas maneiras de pensar, começa-se a perceber que há ausências importantes ou efeitos importantes de gênero. É por isso que me interessei muito por Foucault, em pensar sobre as complexas relações entre conhecimento e poder, nas quais se pode adicionar os efeitos das relações de gênero como formas de poder e mostrar como o conhecimento é construído e influenciado pelas relações de gênero.

Miriam Grossi: Um artigo seu se tornou muito conhecido aqui no Brasil: "Pós-modernismo e relações de gênero".' Seria interessante que você nos falasse um pouco sobre o momento em que foi escrito, o tipo de retorno que você recebeu, ou se provocou alguma discussão ou controvérsia, porque aqui no Brasil você se tornou conhecida através desse texto publicado no início dos anos 1990.

JF: Esse artigo foi escrito no final dos anos 80 e publicado inicialmente na revista Signs. Ele realmente serviu como um tipo de condensação do que acabou sendo meu primeiro livro - Thinking Fragments. Eu estava tentando articular algumas relações entre a teoria feminista, a pós-modernidade e a Psicanálise e pensar sobre os pontos nos quais uma suplementa a outra, e os pontos nos quais elas se corrigem. Tentava pensar um caminho de fazer Filosofia distinto daquele que eu havia aprendido. A forma tradicional de fazer Filosofia era uma luta entre adversários, em que se tentava destruir os argumentos do outro e às vezes aquele argumento que conseguia sobreviver era o argumento vencedor do momento [risos]. Também estava tentando pensar sobre uma forma de fazer Filosofia, que fosse mais coloquial, na qual fosse possível colocar diferentes formas de pensar em diálogo, mas não a partir do ponto de vista de encontrar o caminho verdadeiro ou o argumento vencedor. Achava que, ao colocar em diálogo distintas formas de pensamento, seria possível enriquecer toda forma de 
pensamento e também nos ajudar a refletir de modo mais complexo. Esse artigo era meu experimento com o modo dialógico, que se tornou muito importante para escrever meu primeiro livro. E penso que é porque eu tentava chegar perto das idéias fundantes de cada um desses corpos teóricos, justamente quando as pessoas estavam se interessando nessas teorias, que o artigo se tornou conhecido. Acho que é porque permitiu o acesso a alguns corpos teóricos que muitas pessoas têm dificuldade de entender ou decifrar. $E$ isso se tornou muito importante na teoria feminista porque há um monte de argumentos sobre pós-modernismo em relação àquilo que ele permite como possibilidade de ação feminista, sobretudo o argumento de que você precisa de um sujeito unificado ou uma categoria unificada de mulher para engajar uma atividade política. Nos Estados Unidos isso se tornou uma batalha enorme, se as feministas deveriam ou não se deixar influenciar por certas ideias pós-modernas. Muitas pessoas se opunham muito a essas idéias, especialmente aquelas interessadas no marxismo e em standpoint approaches. E isso também porque sempre houve muitas controvérsias sobre esse tipo de enfoque, especialmente no caso das pessoas de minha geração.

Eu penso que não foi tão importante para mulheres mais jovens porque elas estavam menos investidas na idéia de 'mulher unitária', pois elas cresceram com muito mais consciência da complexidade de raça, sexualidade e das múltiplas identidades das mulheres. Mas considero que a primeira geração feminista estava muito interessada na excitação de ter descoberto essa categoria de mulher, da opressão compartilhada, das experiências comuns. Por isso era muito doloroso para elas passar a pensar sobre mulheres em formas multivariadas e, é claro, isso era politicamente muito envolvente porque mulheres de cor e mulheres homossexuais começaram a se rebelar contra essa idéia de mulher unitária. Portanto, a viagem ao pós-moderno não se deu apenas por motivos teóricos, mas também muito por motivos políticos, dada a percepção de que a categoria mulher realmente só refletia as mulheres de classe média e com educação superior do Primeiro Mundo. E isso era incrivelmente problemático para o feminismo. Mas eu penso que o termo pós-modernismo foi uma espécie de bad guy na disrupção dessa idéia inicial de mulher unitária, que compartilhava solidária e politicamente sua experiência. Muitas mulheres no revival do feminismo ficaram muito ressentidas e se sentiram descolocadas pelas reivindicações das mulheres de cor, de mulheres de fora dos Estados Unidos e das mulheres homossexuais. Por isso acho que todo o debate sobre pósmodernismo teve um subtexto político muito importante e que as feministas jovens estão mais acostumadas com essa área ampliada e contestada. Assim, para elas resulta menos chocante do que para as feministas de gerações anteriores. 
MG: Queria lhe fazer uma pergunta sobre o pós-modernismo. Como é que você vê o pós-modernismo nos EUA? Existe uma ou várias vertentes?

JF: Existem muitas vertentes de pensamento pós-moderno, e faz muita diferença o tipo de abordagem que você adota. Acho que as pessoas que vêm da área de Crítica Literária têm uma visão muito menos política do pós-modernismo. São mais predispostas àquilo que é para mim um erro: pensar que tudo é texto, que tudo é discurso. Para mim, isso demonstra como a profissão influencia a forma de pensar: as pessoas que lidam com texto acabam achando que só há texto. Mas não adoto essa abordagem. Não parto tanto de Lacan, de Derrida. Parto de Foucault, que tem uma abordagem muito diferente, pois ele sempre se interessa pelo poder. Ele entendia o pósmodernismo de uma forma muito política, como se se tratasse de pensar na política de uma maneira diferente. Na sua obra tem muito de reação ao descobrimento do que era Stálin, dos campos da morte, de Hiroshima e do Holocausto. Acho que os norte-americanos partiram de uma vertente muito estreita do pós-modernismo, removido também do contexto histórico e político da França. E como acontece tantas vezes quando as coisas são importadas para os EUA, seu conteúdo político se perde.

Também porque há muitas pessoas da área da Crítica Literária que não têm formação em Filosofia, e para entender Foucault você realmente precisa entender a Filosofia da Ciência, as mudanças na Filosofia, Heidegger e Nietzsche, pois Foucault não faz tanto sentido se você não entende que ele está reconstruindo tanto categorias básicas da Filosofia quanto da Política. Assim, parece que o pensamento de Foucault quase se tornou uma espécie de técnica, mais do que uma forma política de entender o mundo. Porém, minha maneira de interpretar o pós-modernismo não tem a ver com texto e textualidade, mas é, muito mais, um modo de refletir a respeito das formas alternativas de pensar sobre poder e subjetividade. Assim, considero que é muito diferente daquilo que você lê nas abordagens vindas da literatura.

MA: Uma idéia sua reflete uma posição dentro da teoria feminista hoje, segundo a qual precisamos ir além da construção social. Gostaria que explicasse isso mais um pouco e, se puder, nos dizer até que ponto que essa posição está se tornando hegemônica entre as teóricas feministas de hoje, já que você falou sobre a questão das gerações e da importância de continuar avançando.

JF: Bom, eu penso que um dos problemas da construção social 
é que se simplificou de tal modo que, se as pessoas começaram reagindo contra o essencialismo, como uma reação contra a forma biologicista de pensar as mulheres, acabaram indo completamente para o outro lado da dicotomia, ou seja, para a cultura. A perspectiva dicotômica de pensar diz que há por um lado a natureza, que é biologia, o mundo natural, as coisas que não foram tocadas pelos seres humanos, e por outro há cultura, que é puramente humana. Assim, a construção social foi interpretada como as formas em que os humanos constroem a si mesmos e seus mundos. Eu tenho pelo menos dois problemas com esse tipo de perspectiva. Primeiro, que não mexe com a dicotomia natureza-cultura, que para mim é culturalmente produzida. Nós construímos determinadas coisas como natureza e outras como cultura e não pensamos sobre a forma em que nós mesmos somos natureza. É necessário haver maneiras mais complexas de pensar sobre a natureza.

Penso que nisso sou influenciada não só pelo meu trabalho como psicanalista, mas também pelo fato de ter sido bailarina durante muitos anos da minha vida - os bailarinos têm um modo próprio de construir o mundo. Eles falam sobre a memória dos músculos, que os músculos 'se lembram'. O corpo não é um corpo físico inerte. É um ser vivo que realmente organiza tua vida. Você trabalha teu corpo de dentro para fora, você se apresenta através de uma série de posições e você recebe a música dentro do teu corpo e a transforma em movimento. De tal modo que para mim - e também porque estou pensando no meio ambiente e nas formas complexas como nossas atividades transformam o mundo, que por sua vez fazem com que tenhamos de mudar nossas práticas (como no caso da camada de ozônio) - eu sempre quero captar esse aspecto da corporificação.

Penso nisso também por causa da Psicanálise, na idéia de que o inconsciente é simultaneamente psíquico e somático, que para mim é uma idéia muito radical, mas ao mesmo tempo muito pouco aceita: a maneira como as pessoas encenam fisicamente sua vida mental. As pessoas sentem dor de cabeça, e muitas vezes a depressão se manifesta no cansaço ou nas dores no corpo. Você vê sempre esse modo complexo de simbolizar, que pode ser tanto física quanto verbal. Porque gosto muito de pintura, creio que todas as formas não verbais de representar e transformar a experiência são importantes.

Não podemos simplesmente falar sobre a construção social de uma forma que deixe a dicotomia natureza/cultura intata. Esse pensamento emergiu nos séculos XVI e XVII na Europa, ou seja, tem uma história: distinguimos a mente do corpo, a 'natureza morta' que os humanos vão controlar. Distinguimos aquilo que nos torna humanos, nossa razão, nossa capacidade de controlar todos esses objetos mortos. Essa é toda uma forma de pensar da qual, de certa maneira, a construção social ainda 
não se livrou. Eu estou procurando outras maneiras de falar sobre esse jogo de interação complexo que nos leve além daquela dicotomia simples natureza/cultura.

MA: E a Teoria Política? E a política em si, a prática das instituições políticas? Elas não adotam essa abordagem, não incorporam esses elementos na sua forma de fazer ou pensar a política? Talvez seja um bom momento para você fazer um comentário especificamente em relação a sua abordagem não convencional e desafiadora para com a sociedade e a política norte-americana. E, claro, àquilo que você vem trabalhando, o entrecruzamento de gênero e raça.

JF: Bom, vou começar com a Teoria Política. A maior parte do que você vê na teoria política norte-americana continua segregando a teoria política feminista do resto da Teoria Política. E com certeza, a Ciência Política segrega a Teoria Política e também reproduz a segregação entre as pessoas que ali fazem um trabalho feminista e o mainstream da Ciência Política. A Ciência Política continua muito rígida: ou é teoria da escolha racional ou é o comportamento eleitoral. Ela permanece muito pouco influenciada pelas abordagens feministas. Os seus autores continuam pensando no gênero como se fosse simplesmente uma variável, o sexo masculino ou feminino, e como votam as mulheres e os homens. Mas não transformam sua maneira de pensar sobre política. Permanecem no institucional. Você não lê neles o tipo de discussão que você acha a partir de Foucault, sobre práticas disciplinares ou formas não-institucionais de poder. Assim, a Ciência Política norteamericana permanece pouco modificada por qualquer forma transformadora de pensar o mundo que possa incluir influências feministas. E a maior parte dos teóricos políticos não lêem a teoria política feminista. Há uma comunidade muito pequena de teóricas políticas norte-americanas e raramente os outros integrantes do campo disciplinar prestam atenção nelas.

Ainda mais raras são as pessoas que incorporam considerações sobre raça. Mesmo entre as teóricas políticas feministas, penso que não há um reconhecimento mais pleno do entrecruzamento de raça e gênero. Não se percebe sua construção recíproca e como você não pode falar de uma sem falar do outro. Então, há uma ausência crítica. Recentemente saiu uma coletânea de ensaios de Elizabeth Abel, e algumas outras mulheres editaram um volume sobre Psicanálise e raça, e hoje há um grupo de teóricos que trabalham com teoria crítica racial (critical race theory). Mas isso também é pouco incorporado na teoria política do mainstream, ou na teoria política feminista. Eu diria que é uma área do discurso feminista que exige muito desenvolvimento. $\mathrm{E}$ torna meu trabalho um pouco diferente do trabalho que outras 
pessoas fazem, embora, sim, exista uma série de pessoas que estão tentando dar conta dessas perspectivas múltiplas.

MA: E como é que a questão de classe entra nessa história?

JF: Classe é uma questão que ninguém sabe reconstruir. A antiga noção de classe não funciona muito bem no Ocidente contemporâneo. Isso em parte devido às mudanças na estrutura de classes em si, pois torna-se difícil de entender pessoas que são trabalhadores profissionais, ou as companhias cujos funcionários são também proprietários da empresa, como a United Airlines. Se os funcionários são também os proprietários, são trabalhadores ou capitalistas? É um grande debate. Há algumas pessoas que estão tentando revisar as formas de pensar sobre classe social. Mas acho que ninguém consegue lidar muito bem com isso.

Quando se pensa sobre raça e gênero nos EUA, diferentemente da Europa ou da Austrália, as fronteiras entre as classes se complicam muito por causa da questão de raça. Então, quando dou conferências na Europa ou na Austrália as pessoas têm dificuldades de entender a falta de consciência de classe nos EUA. E isso se explica em parte por conta dessa relação complexa entre raça e classe. Durante muito tempo os negros nem podiam se filiar aos sindicatos. Assim, a classe trabalhadora branca participou ativamente da opressão dos negros, e nossas relações de classe são diferentes das da Inglaterra, por exemplo. Mas acho que hoje a Europa Ocidental está tendo de encarar o mesmo tipo de problema que os EUA. Devido à imigração, as tensões que estão ocorrendo em torno de imigração e raça estão se tornando mais evidentes. Na Europa também não há uma boa solução de classe para isso. Acho então muito complicado pensar na questão de classe nas configurações políticas contemporâneas do Ocidente.

MG: Você falou que existem alguns grupos que estudam Teoria Feminista e Teoria Política. Vocês têm alguma rede, algum tipo de reunião anual, ou grupo eletrônico? Qual sua forma de organização?

JF: Bom, existem algumas organizações. Por exemplo, há uma Sociedade para Mulheres na Filosofia que discute algumas dessas questões, um Grupo de Mulheres (Women's Caucus) em Ciência Política e um grupo de trabalho na Ciência Política para o estudo de mulheres e política. É um pouco mais abrangente do que teoria política feminista, mas não existe uma rede específica de teóricas políticas feministas. A maior parte se conhece pessoalmente, pois somos poucas, mesmo que os EUA sejam grandes. Quando as diversas organizações que tratam de Teoria Política fazem suas reuniões, geralmente 
organizam ou promovem umas mesas-redondas sobre teoria política feminista. E há algumas revistas - nenhuma especificamente sobre teoria política feminista - nas quais a teoria política feminista tende a aparecer, como Signs, Feminist Studies ou Women and Politics. São essas as redes que existem.

MA: Talvez você pudesse comentar um pouco sobre a recepção, fora da academia, de todos esses esforços de feministas e teóricos da questão racial. E sobre o rumo que vão tomando as ativistas ou estudiosas feministas, em termos da política neste mundo louco no qual estamos vivendo hoje.

JF: Bom, eu penso que de certa maneira pelo menos o mundo norte-americano tem mudado, que o feminismo trouxe uma série de mudanças nas relações de gênero nos EUA. Penso que as expectativas das pessoas são diferentes. Considero que, de forma não tradicional, as mulheres negras sempre trabalharam fora do lar e isso se deveu parcialmente a questões financeiras. Hoje em dia, no geral, são muitas as mulheres que têm essa expectativa de passar uma boa parte das suas vidas trabalhando, em parte por motivos econômicos, em parte por questões de auto-estima e de compreensão do tipo de poder que provém de uma pessoa que tem uma carreira, um emprego e dinheiro próprios. Penso que houve mudanças, muito interessantes para mim no sentido de ter mais mulheres se envolvendo em atividades físicas e esporte. Há uma legislação nos EUA que exige que se destinem recursos iguais para mulheres e homens no esporte, tanto no segundo grau quanto no nível universitário, de maneira que vemos um envolvimento bem maior de mulheres em vários tipos de esportes. Pareceme que tais atividades podem realmente empoderar as mulheres e mudar sua relação com seus corpos. E me parece também que se tornou menos socialmente correto que as pessoas ajam de maneiras abertamente sexistas ou racistas, mas isso não se aplica igualmente ao comportamento homofóbico. Ainda há muito a se resolver nesse sentido. E talvez isso reflita menos uma mudança na forma de pensar das pessoas, e mais uma dificuldade de se manifestar e ser social e culturalmente aceito. As normas mudaram um pouco. Há mais mulheres, as mulheres são mais visíveis em determinadas profissões. Aqui outra vez diria que as questões de raça têm mudado mais lentamente, e com certeza nas altas esferas de poder até hoje a mudança é quase nula. E parece-me que hoje está se descobrindo - e isso é muito deprimente - que, na organização básica da vida social, muito pouco tem mudado. Assim, em termos das expectativas em relação ao trabalho, este continua sendo organizado sob o pressuposto de que há alguém em casa. As pessoas trabalham 10 ou 12 horas por dia e isso é muito desgastante. As pessoas ainda têm de optar por 
ter ou não filhos, e muitas escolhem não ter em parte porque não é possível combinar com o trabalho. Os EUA são muito atrasados em termos de bem-estar social, saúde e atendimento à infância, e programas nessas áreas, em lugar de progredir, estão piorando.

Agora, em relação ao mais explícito, de certa forma as relações raciais estão melhorando. Com certeza não há o mesmo tipo de violência e as formas mais abertas de discriminação que existiam durante uma boa parte da década de 1960. Mas acho que ainda existem grandes barreiras para as pessoas de cor nos EUA, relacionadas com o tratamento que recebem na vida cotidiana. E parece-me que temos aprendido que muitas dessas coisas não competem tanto ao Estado ou à legislação sobre Direitos ou Liberdades Civis, e isso se conecta com as percepções da teoria feminista ou teoria crítica sobre raça na atualidade quando estas assinalam que temos de levar em conta todas as outras instituições onde o jogo do poder se desenrola. E que muitas vezes são estas as questões mais importantes para começar a pensar: como o trabalho se organiza e como a medicina, a educação e as maneiras de produzir conhecimento e a mídia se organizam. São muitas as outras formas de poder que realmente dizem respeito à organização de raça e gênero. Precisamos de estratégias que não se orientem necessariamente na direção do Estado ou do Poder Legislativo. De fato, é esse tipo de questão que as pessoas estão tentando pensar agora, e acho que um bom exemplo disso são as organizações que vêm se estruturando em torno da AIDS e a pressão pública sobre as companhias farmacêuticas. E isso realmente muda a forma como as pessoas pensam sobre a medicina ou sobre a produção das drogas. Então acho que isso indica muito bem o sentido da política do futuro, pois temos realmente visto os limites de uma abordagem simplesmente judiciária ou legislativa que não põe fim à dominação de raça e gênero.

MG: Gostaria que falasse sobre seus outros livros, já que comentou Thinking Fragments...

JF: Claro. Depois de escrever Thinking Fragments eu escrevi outro livro, chamado Disputed Subjects, e nele escrevi uma série de ensaios para abordar muitas das questões levantadas no primeiro. Assim, incluí artigos sobre como podemos agir politicamente mesmo sem uma idéia de Verdade ou padrões universalistas ou um sujeito unitário. Há um repensar da relação mãe-filha que procura uma maior complexidade e ainda, como 'o maternal' tornou-se um conceito organizador tão importante na teoria feminista. Ainda escrevi um ensaio sobre Kant e sobre os limites que as instituições políticas liberais têm para mudanças nas relações de dominação de raça e de 
${ }^{2}$ Clarence Thomas é um juiz negro da Suprema Corte norteamericana que foi julgado por assédio sexual contra uma de suas assistentes, Anita Hill. gênero. Assim, trata-se de uma série de ensaios que abordam alguns dos desafios ou questões que as pessoas colocam tanto em termos da organização da subjetividade e dos afetos quanto das formas de pensar sobre como se poderia viver a vida política. E meu livro mais recente chamou-se The American Dream in Black and White. Foi publicado em 1998 e realmente tive dois motivos para escrevê-lo: um era para detectar as formas muito específicas em que gênero e raça se constroem reciprocamente e como todo mundo nos EUA é construído através dessas relações sociais que interagem. E para isso eu usei o texto das audiências sobre Clarence Thomas, ${ }^{2}$ para mostrar como a compreensão que as pessoas têm de sua própria subjetividade e sua compreensão da cultura norteamericana se estruturam através de raça e gênero. Esse foi um dos meus motivos.

O segundo motivo para escrever o livro relaciona-se com as críticas que me fazem, de que minha abordagem anula 0 engajamento político. E decidi que, em lugar de entrar em mais um tedioso debate do tipo 'sim, engaja; não, não engaja', eu simplesmente o demonstraria. Quer dizer, queria mostrar como minha abordagem poderia fornecer uma série de insights sobre uma questão política contemporânea. E também que essas questões têm algumas conseqüências políticas concretas, pois uma das que eu abordava nesse livro era a idéia da política identitária, porque Clarence Thomas é um excelente exemplo dos limites da política identitária. É um homem negro, e no entanto sua política é um desastre para qualquer um que se interesse na libertação de raça ou de gênero. Ele tem assumido algumas das posições mais conservadoras na Suprema Corte. E antes de chegar lá, ele já era muito conservador. Algumas pessoas se iludiam com isto: que, sendo ele um homem negro, uma vez chegando aos níveis mais altos do poder, de alguma forma, mágica, sua verdadeira essência como um liberal, um homem negro necessariamente liberal, emergiria. Claro que isso não aconteceu! Assim, eu queria falar sobre essa questão e também usá-la para mostrar a rua sem saída da política identitária. E para mostrar por que não se pode empregar a standpoint theory nem a política identitária. Porque não só não é politicamente útil, como também realmente solapa o esforço para desenvolver formas mais libertadoras de organizar a sociedade. Assim, o livro contém também um argumento político muito especí́fico.

MG: Você trabalha em uma universidade negra. Imagino que seu trabalho ali influencia suas reflexões sobre raça e gênero. Você poderia falar sobre teu trabalho nessa universidade?

JF: Sim, para mim tem sido muito bom nesse sentido. Eu penso que sou 'três vezes minoria' porque são poucas as mulheres, 
negras ou brancas, que são professoras ou ocupam posições de poder na minha universidade. E existe muito anti-semitismo entre as pessoas negras, anti-semitismo não reflexivo, e também a questão de ser uma pessoa branca em uma instituição que é predominantemente negra. Assim, penso que é um treinamento ético e político excelente, porque você não pode tomar como dado que o mundo opera de qualquer forma que é familiar para você. Assim, acho que é muito bom e que é uma experiência que seria muito boa para qualquer pessoa em uma posição de privilégio. Também penso que, porque já faz tempo que dou aula lá e tenho uma boa reputação, tenho oportunidade de ouvir muitas coisas que pouquíssimas pessoas brancas nos EUA escutariam. Meus alunos ficam muito confortáveis falando comigo sobre relações de raça e gênero, sobre os problemas na comunidade negra e como se sentem em relação às pessoas brancas. E mesmo sobre as texturas de sua vida cotidiana: como que é entrar em um supermercado e ter um guarda que te segue, ou não poder pegar um táxi, ou como eles vivem essas questões de raça e gênero mesmo nas coisas mais básicas. E assim me parece que sou muito privilegiada para poder pensar e obter informações sobre como eles pensam raça e gênero e ter a experiência que os meus alunos têm a vida toda, que é de não formar parte da 'maioria'. Acho que isso tem uma influência enorme sobre meu trabalho e por isso sou muito grata a eles.

MG: Você está preparando outro livro agora?

JF: Não, agora não. Tenho escrito muitos ensaios porque anos atrás tive um ano sabático e meio que entrei em uma modalidade ensaística. Acredito que desde que terminei o último livro escrevi mais ou menos seis ensaios. Escrevi dois como resposta a Martha Nussbaum, uma filósofa norteamericana a quem de certa maneira eu admiro, pois ela não é como muitos outros filósofos. Ela se esforça para falar sobre questões de justiça e passa muito tempo na Índia e realmente tenta pensar as relações entre mulheres do Primeiro e do Terceiro Mundo. Mas na minha opinião ela parte de uma orientação filosófica errada. Ela tenta argumentar que há certas capacidades humanas universais e que a justiça trata de possibilitar a realização dessas capacidades. E ela pensa que são universais, que perpassam todas as culturas e podem servir como a base de solidariedade entre feministas. Obviamente tenho muitos motivos para discordar dela. Assim, eu escrevi dois ensaios em relação ao seu trabalho. E escrevi também um trabalho que deve sair em 2003 na revista Signs sobre o livro de Dorothy Dinnerstein The Mermaid and the Minotaur, que teve uma influência enorme entre as feministas quando saiu em 1974, ainda antes do trabalho de Nancy Chodorow no qual ela falava 
de como afeta as pessoas o fato de que as principais responsáveis pelo cuidado e educação das crianças são mulheres. Eu voltei e trabalhei com alguns dos seus argumentos, interessando-me por aquilo que a permitia fazer um certo tipo de afirmação universal. E tinha um interesse particular no seu viés heterossexista não reflexivo, ou seja, o pressuposto do casal heterossexual e como isso se relaciona com certas imagens da maternidade e assim por diante.

E estou também escrevendo sobre Teoria Política e me interessei muito pelo John Rawls. Ele é realmente o mais importante dos teóricos políticos norte-americanos. Seu livro que saiu em 1970, A Theory of Justice, realmente reavivou a Teoria Política, e as pessoas começaram a escrever sobre justiça e política de uma forma que durante muito tempo se desconhecia. Mas penso que, embora também admire seu desejo de justiça e sua consciência da falta de justiça nos EUA, também vejo seu trabalho como um beco sem saída do pensamento liberal abstrato por excelência. Assim, eu quis achar uma forma de falar sobre as noções de justiça nesses dois autores. Escrevi alguns ensaios nos quais faço uma justaposição da sua abordagem com a da escritora Toni Morrison e a perspectiva dos representantes da critical race theory (teoria crítica sobre raça).

E escrevi outro trabalho, pois voltei a ler os três ensaios sobre a sexualidade de Freud, e realmente quis trabalhar mais com a idéia do desejo em Freud e como esse conceito nessa fase da obra dele realmente vem ao encontro das idéias de Foucault sobre o prazer. E também como se pode começar a desenvolver uma ética, pois é isso que Foucault estava tentando fazer antes de morrer - pensar em uma ética que não dependa da razão, porém muito mais da estética e do desejo. Então sempre me interessei em pensar sobre justiça e queria desenvolver mais algumas dessas idéias. São esses os campos em que venho trabalhando nos últimos anos.

MG: Discutimos e falamos sobre a recepcão do teu trabalho na Austrália, na Nova Zelândia e no Brasil. Você pode nos dizer alguma coisa sobre como é percebida como teórica feminista nesses lugares que você visita, e talvez como é comparada com outras teóricas feministas norte-americanas?

JF: Quando estava na Austrália, foi muito fascinante para mim, porque as feministas de lá têm uma teoria feminista muito sofisticada. A Austrália em si está em uma busca de identidade: faz parte do Ocidente? Faz parte do mundo asiático? E qual sua relação com o povo aborígine? Por outro lado, as pessoas que chegaram à Austrália tinham sido presas, pois os ingleses usaram a Austrália como colônia penal - com as prisões da Inglaterra cheias, mandavam os presos para a Austrália. Assim, 
por um lado eram presos, e por outro foram os responsáveis pela destruição da vida dos aborígines. E lá encontrei feministas muito interessadas em Foucault, em pensar sobre os limites de um certo tipo de programa de bem-estar social do Estado e, portanto, de alguma maneira elas pensam em formas mais sofisticadas do que muitas feministas norte-americanas. Penso em termos da Europa, pois uma coisa que sempre tenho valorizado é a capacidade de muitas feministas do continente europeu de manter simultaneamente idéias múltiplas, como as feministas italianas e algumas das feministas francesas. Considero que isso se deve à tradição filosófica do continente, de certa forma, um tipo de sensibilidade complexa em relação às formas múltiplas do pensamento que pode ser incentivado nesse contexto. Acho que me ajudou muito, especialmente para pensar sobre questões de subjetividade. Uma parte do trabalho das feministas européias veio a ser muito importante para o desenvolvimento do meu pensamento. E acho maravilhoso, como mencionei anteriormente, que as pessoas façam perguntas tão diferentes. Por exemplo, a experiência européia em relação à classe é muito específica.

Na Europa, alguns conceitos sobre feminilidade são muito interessantes, e existem também diferenças culturais importantes. Acho engraçado que um certo tipo de feminismo norte-americano (que até certo ponto está mudando) herdou uma certa tradição americana puritana. E, você sabe, durante muito tempo uma feminista séria não deveria ligar para sua aparência, nem para muitos tipos de prazeres sensuais, e uma parte da esquerda norte-americana sempre foi esvaziada de qualquer sensibilidade estética. Enquanto isso, na Itália, o Partido Comunista organiza feiras, festas e produz arte que vai além do realismo socialista. Valorizam assim os prazeres da vida. Uma coisa que sempre acho interessante na ltália e na França é exatamente que há uma cultura feminista diferente. Sabe, na primeira vez que fui para a Itália para uma conferência fomos a um restaurante e serviram um jantar maravilhoso, e todas as mulheres estavam vestidas com muita elegância. Bebemos um vinho maravilhoso e as pessoas se levantavam e cantavam ópera. Gostei mesmo! Acho que é muito bom você ter chance de conhecer outras culturas e maneiras de ser. Isso reforça a idéia das múltiplas formas em que se pode viver a vida. E mesmo pode ser uma prática e dar contribuições políticas importantes. Assim, creio que aprendi muito também nas minhas viagens sobre como as pessoas pensam. E, claro, agora os europeus estão tendo de lidar com algumas das mesmas questões de raça que acontecem nos EUA. Dessa forma, eu consegui apoiar um pouco as pessoas na Europa e na Austrália, em termos de ajudá-las a desenvolver um discurso sobre raça que lá está ainda muito pouco desenvolvido. Da mesma maneira, elas poderiam dizer que nosso discurso sobre 
classe está pouco desenvolvido. E assim eu penso que é nesse sentido que consegui levar para fora algumas das experiências e reflexões norte-americanas, de um jeito que se torna útil para o contexto europeu.

MG: Você gostaria de acrescentar alguma coisa?

JF: Acho que a única coisa que acrescentaria é que provavelmente meu trabalho torna-se diferente, em parte, por causa da minha longa prática como analista. Penso que quando você lida com pacientes - potencialmente, pois não necessariamente tem que acontecer - a prática analítica modifica a forma como você usa a teoria psicanalítica. Ou seja, quando você vê quão difícil é começar a compreender outra pessoa, e quão dolorosos e lentos são os processos subjetivos, você trata a teoria de forma diferente - ao não se tornar um tipo de receita que você aplica aos textos, ela adquire toda uma textura diferente. Trata-se de um processo e exige um tipo de respeito. Você não pode simplesmente encaixar uma coisa em uma categoria, pois as categorias, na prática, só se tornam úteis em uma certa medida se não forem vistas como esquemas infalíveis, nem fórmulas para entender o que acontece com outro ser humano ou entre os seres humanos. Assim, penso que as minhas formas de usar a Psicanálise são muito influenciadas por minha prática clínica e tornam-se muito diferentes da maneira como algumas feministas da Psicanálise trabalham com a teoria psicanalítica. Eu valorizo muito o que aprendi com os meus pacientes em termos da teoria psicanalítica e em termos mais gerais, sobre a subjetividade. Em parte é por isto que eu encontro sentido no pensamento pós-moderno: quando você vê quão complexa é a organização de um indivíduo ou entre indivíduos, e quando você observa como, após anos e anos de analisar alguém, muita coisa nessa pessoa continua sendo misteriosa. Há muito em cada um de nós que é misterioso, e qualquer idéia de que você possa chegar a alguma essência do sujeito ou alguma organização estável dele torna-se muito estranho. Para mim, é realmente um milagre chegar a entender alguma coisa sobre outra pessoa, e é por isso que conceitos como aquele de Habermas (do universal speech act) é simplesmente bizarro. Você sabe, há muito em nós que não só não conseguimos expressar através da linguagem mas que também nem sequer temos acesso àquilo, se o encenamos através do corpo ou da língua. Então eu penso que minha prática analítica realmente influencia minhas formas de pensar não só sobre teoria psicanalítica mas também sobre a subjetividade.

MG: Qual o lugar do corpo na tua Psicanálise? 
JF: Bom, em primeiro lugar eu vejo muitas pessoas com distúrbios de humor; sofrem de depressão ou de ansiedade, ou seja, nisso você já enxerga a interação do mental e do físico. Quando você está em depressão, isso modifica tua forma de pensar, teu apetite, teu sono, mexe com sua memória - a pessoa tem uma aparência diferente, o rosto muda, com freqüência sua fala é mais lenta. Assim, você tem de ver a pessoa como estando sempre dentro do seu corpo, e olhar para seu estado somático para obter indícios daquilo que lhe acontece. E também porque você recebe muita informação a partir da postura corporal, do tom de voz, da expressão facial, pois há pesquisas que sugerem que até $75 \%$ da informação que recebemos sobre outra pessoa não vem através daquilo que fala. É engraçado, uma paciente minha me contou que a companhia de Internet para a qual trabalha antes conduzia todos seus negócios por e-mail, mas agora começaram com o que chamam de face time porque descobriram que você não pode realizar determinados tipos de planejamento ou organização sem os corpos presentes. Simplesmente não funciona! Então promovem reuniões onde fazem as mesmas coisas que fariam pela Internet mas com as pessoas sentadas em uma mesma sala.

Mesmo na minha interação com meus pacientes pergunto para eles o que comem. E também receito exercício para eles, não só porque melhora o estado de ânimo, mas porque essas coisas proporcionam um maior senso de competência e bem-estar. É muito importante estar dentro de teu corpo. Isso traz grandes efeitos emocionais, mas muitas pessoas não estão dentro de seus corpos; elas fazem suas vidas através de uma cisão, vivendo "dentro da mente". Ou seja, eu fico muito atenta à maneira como vivem, sua vida corporal, e isso se relaciona com Foucault. Acho que uma das coisas mais importantes que Foucault nos ensina é que, em parte, o problema do discurso sobre o corpo reside na sua transformação no discurso da sexualidade, que só temos dois modos de viver em e pensar sobre o corpo: em relação à disciplina e ao controle, ou à sexualidade. Mas há muitas outras formas de existir, como seres corporificados. Isso faz parte daquilo que eu tento abrir para as pessoas: múltiplas formas de estar no corpo, seja ouvindo música, seja olhando um quadro. Eu me interesso muito por todas as múltiplas maneiras de envolver-se no mundo físico, e isso influencia muito minha prática analítica. Não é só questão de interpretar as fantasias dos pacientes ou prestar atenção às palavras que usam. Isso, claro, é importante. Mas não é só isso que deve entrar em uma análise. Acho que uma coisa que faz muita falta em Lacan é a interação entre os feeling-states, entre paciente e terapeuta. E o/a analista tem de prestar atenção aos sentimentos que o paciente está produzindo nele/a e como isso se relaciona com o que acontece com o paciente. $O$ 
analista tem de fazer que os pacientes se sintonizem com os feeling-states dele próprio, que nem eles mesmos estão percebendo, de ter raiva ou se sentir abandonado. Existe toda uma linguagem. Nós construímos uma linguagem das emoções, uma linguagem que possa ajudar os pacientes a lidar com esses feeling-states, dar-lhes nomes, e organizá-los e assim por diante. Isso você não consegue fazer dentro da abordagem lacaniana.

\section{Referências bibliográficas}

DINNERSTEIN, Dorothy. The Mermaid and the Minotaur: Sexual Arrangements and Human Malaise. New York: Harper and Row, 1976.

FLAX, Jane. Thinking Fragments: Psychoanalysis, Feminism, and Postmodernism in the Contemporary West. Berkeley: University of California, 1990.

. "Pós-modernismo e relações de gênero". In: HOLLANDA, Heloísa Buarque de (Org.) Pós-modernismo e política. Rio de Janeiro: Rocco, 1991. p. 217-250.

. Disputed Subjects: Essays on Psychoanalysis, Politcs, and Philosophy. New York: Routledge, 1993.

. The American Dream in Black and White: The Clarence Thomas Hearings. Ithaca: Cornell Univeristy Press, 1998.

FREUD, Sigmund. Tres ensayos para una teoría sexual. Obras Completas. Tomo II, Madrid, Biblioteca Nueva, 4. ${ }^{a}$ Ed., 1981, p. 1.169-1.363.

RAWLS, John. A Theory of Justice. Cambridge: Belkap Press of Harvard University Press, 1999.

Tradução de Miriam Adelman e Miriam Grossi Revisão técnica de José Renato de Faria e Luzinete Simões Minella 